\title{
Creating Stories of Science
}

\author{
Amanda C. Niehaus ${ }^{\mathrm{a}}$ \\ Corresponding author: Amanda Niehaus (a.niehaus@uq.edu.au) \\ The University of Queensland, St Lucia, Australia
}

Keywords: creative writing, autobiography, narrative, science communication, empathy

\begin{abstract}
Researchers, academics, and students in the STEM fields can share their experiences through more than academic papers and reports. In fact, modes of writing like fiction can bring science to new audiences and may generate empathy in both reader and writer. Here, I describe the value of creative writing and offer prompts that will enable scientists of all career stages to investigate their environments, motivations, and fears on the page - as I did in the writing of my first novel, The Breeding Season, which was based on my own research.
\end{abstract}

\section{Introduction}

Automation, digitisation, and the global economy are disrupting the linear career trajectory of the past. The graduates of today will need to refresh, grow and adapt their skills to seventeen different jobs in five different careers over their lifetimes (Foundation for Young Australians, 2017). Few will end up where they began. But no matter the career, science graduates will remain - fundamentally - scientists, and the critical, scientific thinking they develop in their undergraduate curriculum will enable them to promote and advance scientific ideas, policies, and perspectives throughout society. This is important, particularly in a modern era rife with scepticism and misinformation (Kavanagh \& Rich, 2018; Scheufele \& Krause, 2019). We will depend on these young scientific thinkers to communicate, collaborate, empathise and generate empathy, and those who can translate their own or others' scientific work most effectivelyin whatever job, form, or context - will have a greater impact on the world (American Chemical Society, ACS, 2017; Freeling, Doubleday, \& Connell, 2019).

Modern science students need a vast toolkit for the communication of ideas, and we might encourage them to be open to more than reports and research papers. Those who can write fiction or poetry or memoir should be encouraged to do so, and provided with the skills to weave their scientific experiences and perspectives into their creative work. Too many scientific outcomes are locked behind paywalls, isolated from the real lives that people live, and their interpretation is left to writers with varied levels of experience (and pressure), politicians, comment threads, and social media: 'facts' on Facebook (ACS 2017) or the opinions of friends, colleagues, or virtual strangers (Freeling et al., 2019). Negative portrayals of scientists in the press and popular media exacerbate a growing distrust of science. Scientists on television and in movies are routinely characterised as cold, suspicious, greedy, dangerous, or mad (Flores, 2002), and these and gender-based stereotypes perpetuate views of science as a lonely, egoistic, masculine discipline (Steinke, 2017). By creating narratives of science in personal or fictional stories, scientists can engage diverse audiences, and do so more persuasively (Dahlstrom 2014); stories generate empathy in audiences that can translate into short- or long-term changes in behaviour (Winner, 2018), so stories about science and scientists can be an important tool for communicating science in the world. Scientists of all career stages should learn to tell their own stories, and tell them in diverse forms. 
Like our graduates, I am a scientist and always will be. But my approach to the profession has changed these last few years: I no longer do the pipetting, husbandry, trapping, or statistics. Instead, I work as a freelance and creative writer, helping scientists communicate their research better in grants or papers, and telling the stories of scientists in my short fiction, essays, and novels. In my education, creative writing happened despite all that I'd been taught, not because of it. Each of us has a unique worldview, shaped by our knowledge and experiences. My undergraduate education was a broad, North American one, yet it was not interdisciplinary: my history classes focused on history, psychology on psychology, chemistry on chemistry. The classes I took in the humanities did not examine the place of science in literature, and my classes in science - which were most of them, being a biology major-trained us to write only for academic audiences. We did not look for science or scientists in works of fiction, essay, or film; we did not discuss the role of science or scientists in modern or historical societies, aside from the most famous examples (and those usually men). In fact, to value creative, subjective writing seemed contrary to the fundamental objectivity required in science. It felt frownedupon.

In my thirties, after an MSc and a PhD in animal ecology, I re-trained to acquire the skills I needed to write for non-academic audiences. I took classes and workshops that taught me how to hook a reader with a strong beginning, how to write more as I speak, and how to create a character that lives and breathes on the page (and in the mind). We often write research papers as though science is linear; in essay and fiction, we can experiment by juxtaposing disparate ideas, weaving story- or time-lines, and relate scientific concepts directly to our own or our characters' lived experiences. Scientific facts are one kind of truth, but for many people, truth is something that must be connected to the everyday world, and to everyday lives. If we are to make the work we do more inclusive, then we need to consider the various audiences that we might connect with through our writing and try to imagine how science might impact their worlds.

This year, I've published my first novel, The Breeding Season (Allen \& Unwin, 2019), and it weaves my own experiences as a researcher of birds, antechinuses and northern quolls with the biological bases of reproduction, trade-offs between sex and death, and work-life balance. It is the story of a marriage; a story of science and art; and a love story. I'm far from the first to write about science or scientists - recent years have given us many great examples in Australia and beyond, including Krissy Kneen's Wintering (Text, 2018) and Stella-nominated An Uncertain Grace (Text, 2017); Sarah Hall's The Wolf Border (HarperCollins, 2015); Hope Jahren's award-winning memoir, Lab Girl (Knopf, 2016); and many, many others. I encourage you to start noticing these kinds of books and the perspectives they share, to think of them as a form of science communication, and share them with friends and students. Novels reflect the stories of our lives, and illuminate aspects of scientific work that may seem mundane to scientists (and exciting to others). It is easy to forget that fieldwork, labwork, modelling, and experiments are far from many peoples' experiences - and entirely unknown if we don't share them.

A great deal of fiction comes from real life-personal experiences, observations, ideas, and fears. The characters in The Breeding Season, and the short story-version, 'Breeding Season,' that I wrote first (Overland, 2017), are me, versions of me, or projections of who I could become, under the right circumstances. These characters do the work I've done in the field and lab and office, and they reflect my fears of death and failure. In the midst of crisis, people seek comfort in the rules they know best: Elise is a scientist who (like me) uses her research to deal with terrible losses, 'getting on with life' in whatever way she can; her husband, Dan, looks to 
words and art. Writing their lives has clarified my own views of the world, illustrating how my varied experiences shaped my perspectives. Self-awareness is an important first step toward empathy (Bockler et al., 2017), and empathy integrates us into the world.

Stories can take any shape, any length, and a 70,000-word novel is a difficult place for anyone to begin. Instead, short stories are simpler, shorter, and tend to focus on one or two characters, one or two settings, over a limited period of time. Stories are built from a simple 'biochemical' formula, much in the same way we write research papers:

the way things were + a catalyst $=$ something new

We reference the past research in our field (the way things were), identify a gap that must be filled (a catalyst), and further the field with new results or interpretations. For stories, it is the character that must respond to the catalyst, by changing their viewpoint, emotions, or life course in some key way - or by pointedly not doing so. Many of our favourite characters in books, movies, and on television become wealthy, powerful or successful, find happiness, or understand themselves more deeply as a result of the catalyst that upsets their norm.

Let's play with stories based on lived scientific experiences, because it is always easier to begin with the truth, and because the world needs more accurate portrayals of science and scientists. These are exercises that I've used in my own writing: asking myself, chapter by chapter, how can I push these characters farther from where they want to be? Make it harder for them to get what they want?

In each of these exercises, set a timer for at least 10 minutes and free-write. Free-writing is simply putting pen to paper and not stopping until the timer goes off - don't stop writing, even if you have to repeat yourself or write 'I don't know what to say.' Trust me, the words will come. And I recommend using pen and paper for this rather than a computer, which makes it too easy to edit as you go.

\section{Entering the world of fiction: A few exercises}

\section{Who is a scientist?}

When I was little, I always pictured a scientist as a man in a white lab coat, gazing into a test tube or microscope with an impractical pipe dangling from his mouth. Because current occupational health and safety regulations prohibit that kind of thing, and because we all know better, let's describe a scientist more like we are-whoever we are. This will be the main character of the story.

What do they look like? What do they want more than anything? What are their favourite things about science? What do they fear? This can be you, a friend, a stranger-anyone, really-but it's definitely easier to describe someone in person or using a printed or online image. I choose Hollywood actors as the physical basis for my characters, and mine my own hopes and fears for their inner spaces.

\section{What does a scientist do?}

Describe the scientist's everyday job. Do they Elliott-trap antechinuses in the wild, like Elise does in my story and novel? Describe the actions of the work, but also the details - the forest, the metal traps, the stand for the pipettors, the lizard skeleton on the green mat. The pictures on the wall. Use all your senses. What do the chemicals smell like? Are they dangerous? How would you describe the colours of things using other scientific or nature-based terms? What 
does the aquarium or $-80^{\circ} \mathrm{C}$ freezer sound like?

\section{The scientist makes a mistake}

This is important, because even though science is built on testing ideas and improving them, we don't often share our mistakes publicly. Mistakes make us human, connect us to everyone else in the world who also make mistakes. So imagine that the scientist (maybe you) does something wrong. They spill something, add A to B instead of C, open the trap to find a snake has eaten their antechinus, get a university Land Cruiser stuck in the sand. What happens?

Then, how do they/you respond in that first moment? Describe the setting in as much detail as you can: the physical spaces, light or darkness, the sounds around them, the feeling in their/your body when they/you realise what they/you have done.

What are the possible consequences of this mistake - on an immediate, local, or global scale? To the scientist? The field of science? The physical world and all the people in it?

\section{The scientist makes a choice}

The mistake has happened; there is no going back. This is where the most fun happens, because the scientist must then make decisions that change the trajectory of their life irrevocably. They might fix the mistake, or cover it up; but their choices will have further consequences that affect their hopes and dreams or the hopes and dreams of others. What does the scientist decide to do in response to their mistake, and how does it change their world or world-view?

These questions can help scientists of all career stages to create narratives of their experiences. These may become stories to share with the world or that simply help them understand their own fears and motivations, find what 'sparks joy' in their work, and contextualise their working behaviours and relationships. I certainly understand my own relationship to science more deeply as a result of writing my novel, and this understanding helped me to let go of my early ambitions to be an academic research scientist and transition into a career based on writing and crossing the so-called science-art 'divide'.

\section{Acknowledgements}

My scientific research and writing on antechinuses and northern quolls were undertaken during a DECRA fellowship by the Australian Research Council at The University of Queensland.

\section{Disclosure statement}

In accordance with my ethical obligations as a researcher, I am reporting that I have referenced my own novelin which I have financial interest—in the writing of this manuscript.

\section{References}

American Chemical Society (2017). Top 10 trends driving science.

Bockler, A., Herrmann, L., Trautwein, F-M., Holmes, T., \& Singer, T. (2017). Know thy selves: Learning to understand oneself increases the ability to understand others. J Cognitive Enhancement, 1, 197-209.

Dahlstrom, M.F. (2014). Using narratives and storytelling to communicate science with non expert audiences. PNAS, 111, 13614-13620.

Flores, G. (2002). Mad scientists, compassionate healers, and greedy egotists: The portrayal of physicians in the movies. J National Medical Association, 94, 635-658.

Foundation for Young Australians (2017). The new work smarts: Thriving in the new work order.

Freeling, B., Doubleday, Z.A., \& Connell, S.D. (2019). How can we boost the impact of publications? Try better writing. PNAS, 116, 341-343.

Hall, S. (2015). The wolf border. USA: HarperCollins.

Jahren, H. (2016). Lab Girl. USA: Knopf. 
Kavanagh, J., \& Rich, M.D. (2018). Truth decay: An initial exploration of the diminishing role of facts and analysis in American public life. Rand Corporation.

Kneen, K. (2017). An uncertain grace. Melbourne: Text.

Kneen, K. (2018). Wintering. Melbourne: Text.

Niehaus, A.C. (2019). The Breeding Season. Sydney: Allen \& Unwin.

Niehaus, A.C. (2017). 'Breeding Season.' Overland, 228, 26-30.

Scheufele, D.A., \& Krause, N.M. (2019). Science audiences, misinformation, and fake news. PNAS, 116, 76627669.

Steinke, J. (2017). Portrayals of female scientists and engineers in popular films. Science Communication, 27, 27-63.

Winner, E. (2018). How art works: A psychological exploration. London: Oxford Scholarship Online. 